\title{
A comparison between different materials with mechanocaloric effect
}

\author{
Ciro Aprea $^{1}$, Adriana Greco ${ }^{2}$, Angelo Maiorino ${ }^{1}$, Claudia Masselli ${ }^{1 *}$ \\ ${ }^{1}$ University of Salerno, Via Giovanni Paolo II 132, Fisciano (SA) 84084, Italy \\ ${ }^{2}$ University of Naples "Federico II", P. le Tecchio 80, Naples 80125, Italy
}

Corresponding Author Email: cmasselli@unisa.it

https://doi.org/10.18280/ijht.360304

Received: 1 June 2018

Accepted: 8 August 2018

\section{Keywords:}

caloric cooling, mechanocaloric, elastocaloric, barocaloric, caloric effect, caloric materials

\begin{abstract}
Caloric refrigeration can be a viable alternative to the traditional vapour compression technology since a caloric solid refrigerant has zero vapour pressure and therefore is ecological with no direct Ozone Depletion Potential and zero direct Global Warming Potential. Caloric refrigeration embraces four main cooling techniques, each one based on a different caloric effect. This paper is focused upon materials that display mechanocaloric properties, with a transition induced through the application of variable pressure (barocaloric cooling) or uniaxial stress (elastocaloric cooling). Materials that display solidstate caloric effects driven by applied pressure/stress could lead to more accessible and economic technological solutions. By means of a two-dimensional mathematical model an energy analysis is performed with the most performing elastocaloric and barocaloric materials to explore the potential of mechanocaloric cooling. Temperature span, cooling power and coefficient of performance have bene evaluated. Results demonstrate best mechanocaloric materials, like $\mathrm{Cu}_{68.13} \mathrm{Zn}_{15.74} \mathrm{Al}_{16.14}$ and $\left(\mathrm{NH}_{4}\right)_{2} \mathrm{MoO}_{2} \mathrm{~F}_{4}$, provide energy performances better than those of traditional vapour compression plants.
\end{abstract}

\section{INTRODUCTION}

Worldwide, about $18 \%$ of the overall energy consumption originates from refrigeration. Most modern refrigeration units are based on vapour compression plants, which consists of compressing and expanding a refrigerant fluid in vapour phase. This conventional technology is strictly connected to the characteristics of the refrigerant fluids and has a considerable environmental impact [1-5]. The impact is related to both the potential of disruption of the stratospheric ozone layer (ODP, Ozone Depletion Potential) and the greenhouse effect (Global Warming Potential, GWP) of the refrigerant fluids adopted. The refrigerant fluids, therefore, damage the environment both directly and indirectly. The first kind of pollution comes off when the refrigerants are release in the atmosphere causing the ozone depletion and the greenhouse effect (direct effect). The indirect pollution is linked to the energetic efficiency of the plant: for the same refrigerant energy as worse is the energetic performance of a refrigerant fluid as greater is the quantity of electrical energy requested. That means a greater quantity of carbon dioxide emitted into the environment, because in a lot of country the electrical energy is obtained by means of the combustion of the fossil fuels (indirect effect). In order to reduce the ozone depletion and the greenhouse effect in the past the CFC (chlorofluorcarbons) fluids were replaced by HCFC (hydrochlorofluorocarbons) and HFC (hydrofluorocarbons) fluids; only the last ones, presenting chlorine fully replaced by the hydrogen, are not harmful for the ozone layer [6-7]. Unfortunately, the HFC fluids present energy performance lower than the ones of $\mathrm{CFC}$ and HCFC fluids damaging indirectly the environment; moreover, the HFC fluids are not fully harmless with reference to the greenhouse effect. The vapour compression plants operating with the carbon dioxide seem to present low environmental impact but the electric energy consumption is greater than the plants working with the classical fluids (HCFC and HFC); for this the "indirect" contribution can be very meaningful. Next to innovative measures [8-9] taken for reducing energy consumption of vapor compression plants the need the need arises to find alternative solutions to vapor compression itself. Because of these environmental problems, solid state refrigeration can be a practical alternative to the traditional vapour compression technology [10]. Since some decades ago some researchers have begun to consider solid state refrigeration an alternative both because of the environmental problems and because of the technical problems, resulting a solid based refrigerator less complex than a vapour compression system thanks to the absence of the compressor and of the lamination valve. A solid refrigerant has essentially zero vapour pressure, and therefore is ecologically sound with no direct Ozone Depletion Potential (ODP) and zero direct Global Warming Potential (GWP).

Caloric refrigeration embraces four main cooling techniques, each one based on a different caloric effect. As a matter of fact, these techniques are linked to the group of materials that show a magnetocaloric, electrocaloric, elastocaloric and barocaloric effect. This technology is founded upon caloric effect, detected in in ferro-caloric materials [11] manifesting itself as a temperature change as a consequence of a variation of an applied driving field in an adiabatic process. Dually, the same field variation happening in isothermal process determines an entropy variation, as described respectively as follows:

$\Delta s=\int_{Y_{0}}^{Y_{1}}\left(\frac{\partial X}{\partial T}\right)_{Y} d Y$, 
$\Delta T_{a d}=-\int_{Y_{0}}^{Y_{1}} \frac{T}{C}\left(\frac{\partial X}{\partial T}\right)_{Y} d Y$

(a)

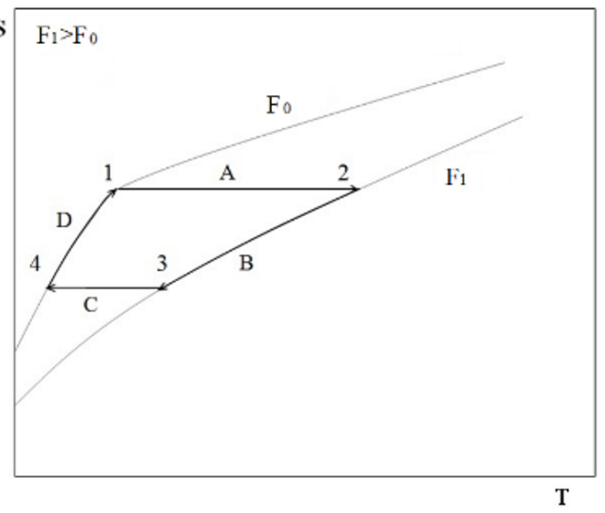

(b)
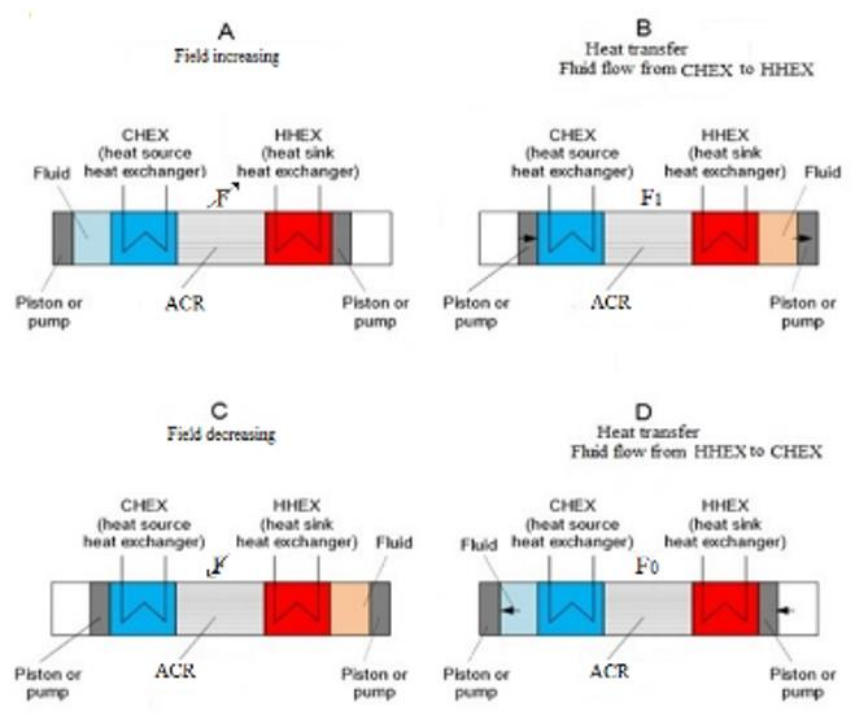

Figure 1. (a) Brayton cycle; (b) ACR cycle.

The nature of the driving field particularizes the caloric effect [12]. Magnetic fields applied to a magnetocaloric materials give rise to magnetocaloric effect (MCE) [13-15] where $\mathrm{Y}=\mathrm{H}$ and $\mathrm{X}=\mathrm{M}$, electric fields to electrocaloric effect (ECE) [16] where $\mathrm{Y}=\mathrm{E}$ and $\mathrm{X}=\mathrm{P}$, mechanical stress to elastocaloric effect (eCE) [17], where $\mathrm{Y}=\sigma$ and $\mathrm{X}=\varepsilon$, pressure field to barocaloric effect (BCE) [18] where $Y=-p$ and $\mathrm{X}=\mathrm{V}$. Caloric effects are exploited in a Brayton based thermodynamical cycle [19] (Figure 1 (a)) applied to an Active Caloric Regenerator (ACR), made of the solid-state caloric refrigerant and acting both as refrigerant and regenerative medium to recover heat fluxes. ACR counts four processes, reported in Figure 1 (b), executed sequentially and cyclically, applied to a regenerator. It is placed between a cold and a hot reservoir (CHEX and HHEX), subjected to a variable flied and free to be crossed by a thermo-vector fluid. The four processes are:

a) adiabatic field increasing;

b) fluid flows from cold to hot side;

c) adiabatic field decreasing;

d) fluid flows from hot to cold side.

During the field increasing process (A), the external field applied to the caloric material, is increased until reaching the maximum value $\left(\mathrm{F}_{1}\right)$ while the fluid is not flowing, causing the increasing of the material's temperature, due to caloric effect. In the second stage (B), the field remains constant and the cold fluid crosses the ACR from the cold to the hot side, thus cooling the regenerator and rejecting heat in the external environment through the hot heat exchanger. When in the third stage (C) the field is reduced until reaching the minimum value $\left(\mathrm{F}_{0}\right)$, while the fluid hasn't any motion, the regenerator sees another decrement in its temperature, thanks to caloric effect. As a final stage (D), while the field is absent, the fluid flows across the regenerator from the hot to cold side, cooling itself and then reaching the cold heat exchanger, where it absorbs heat from the latter, producing a cooling load.

In this paper attention is focused on solid materials that display mechanocaloric properties, with a transition induced by means of pressure or uniaxial stress. There are a lot of review papers dealing with magnetocaloric [20-22] and electrocaloric materials [23-25], but there a very few papers on mechanocaloric materials. Magnetocaloric materials and permanents magnets are mainly based on rare-earth compounds, whose production is very costly and ecologically detrimental [26-29]. Moreover, large magnets are necessary to apply the high fields (at least $1.5 \mathrm{~T}$ ) required to produce a significant MCE, representing a practical problem for commercial devices. In turn, electrocaloric materials present risk of breakdown at high electric fields and are limited to thin film materials.

Therefore, materials that display solid-state caloric effects driven by applied pressure/stress could lead to more accessible and economic technological solutions.

Elastocaloric cooling, also known as thermoelastic cooling, has been recognized as the most promising technology in the field of solid-state refrigeration [30]. It is based on latent heat associated with the martensitic phase transformation process, which has been found in Shape Memory Alloys (SMAs) when they are subjected to cyclic uniaxial loading and unloading stresses. The SMAs are characterized by the mechanical property that they remember the original shape and can return to the pre-deformed shape. The SMA is initially fully austenite under the stress-free state at the application temperature. Then the stress is imposed on the SMA, when it exceeds the "saturation stress" of phase change, the austenite starts to transform into the martensite phase. During the phase transformation, an exothermic process occurs, and latent heat is released to the ambient or, under adiabatic conditions, the material is heated. When the stress is removed, the reverse phase change from martensite to austenite takes place once the loading stress decreases below the "saturation stress" of phase change. In this case an endothermic process occurs, and heat is absorbed from the ambient or, under adiabatic conditions, the material is cooled. In this investigation the choice of the promising elastocaloric refrigerants range has fallen upon two kinds of mechanocaloric materials which show giant effect in the room temperature range:

- the class of $\mathrm{Cu}-\mathrm{Zn}-\mathrm{Al}$ crystals: particularly $\mathrm{Cu}_{68.13} \mathrm{Zn}_{15.74} \mathrm{Al}_{16.13}$ [31] that, for stress changing among $[0 ; 140] \mathrm{MPa}$, shows constant values of $\Delta \mathrm{s}$ $(21 \mathrm{~J} / \mathrm{kgK})$ and $\Delta \operatorname{Tad}(16 \mathrm{~K})$ at room temperature.

- Ni-Ti polycrystals due to superelastic behaviour showing a maximum $\Delta \mathrm{T}_{\mathrm{ad}}$ of about $25 \mathrm{~K}$ at $350 \mathrm{~K}$ when driven by uniaxial stress of $\Delta \sigma=900 \mathrm{MPa}$ [32].

In barocaloric materials the transition is sensitive to external hydrostatic pressure [33]. In the number of barocaloric candidates for room temperature refrigeration, the 
investigation has focused upon three distinct materials:

- the (NH4) ${ }_{2} \mathrm{MoO}_{2} \mathrm{~F}_{4}$ oxyfluorides [34], direct $\mathrm{BCE}$ material, whose $\mathrm{T}_{\text {peak }}$ is about located around $272 \mathrm{~K}$ considered for three different pressure fields applied;

- the hexagonal Ni2In-type MnCoGe0.99In0.01 [35] exhibiting an inverse barocaloric effect due to a pressure-driven orthorhombic-hexagonal magnetostructural transition. The transition for
MnCoGe0.99In0.01 occurs around $298 \mathrm{~K}$ with a $\Delta \mathrm{Tad}$ of $-18.3 \mathrm{~K}$.

- $\quad$ vulcanized natural rubber (V-NR) [36] that show an increase of temperature change due to $\mathrm{BCE}$ with the initial temperature, reaching values up to $11.13 \mathrm{~K}$ at $333 \mathrm{~K}$ for an applied pressure of $173 \mathrm{MPa}$.

In Table 1 are reported the main characteristics of the mechanocaloric materials considered in the present paper.

Table 1. Characteristics of the mechanocaloric materials

\begin{tabular}{|c|c|c|c|c|c|}
\hline Material & $\mathbf{T}_{\text {peak }}[\mathbf{K}]$ & $\Delta \sigma[G P a]$ & $\Delta \mathbf{T}_{\mathrm{ad}}[\mathbf{K}]$ & $\rho\left[\mathrm{kg} / \mathrm{m}^{3}\right]$ & $\mathbf{k}[\mathbf{W} / \mathbf{m K}]$ \\
\hline $\mathrm{Cu}_{68.13} \mathrm{Zn}_{15.74} \mathrm{Al}_{16.13}$ & 234 & 0.14 & 16 & 7700 & 179 \\
\hline NiTi & 350 & 0.9 & 26 & 6450 & 15 \\
\hline$\left(\mathrm{NH}_{4}\right)_{2} \mathrm{MoO}_{2} \mathrm{~F}_{4}$ & 272 & $\begin{array}{l}0.9 \\
0.7 \\
0.5\end{array}$ & $\begin{array}{l}18 \\
15 \\
12 \\
\end{array}$ & 2200 & 1 \\
\hline $\mathrm{MnCoGe}_{0.99} \operatorname{In}_{0.01}$ & 298 & 0.3 & 18.3 & 7900 & 65 \\
\hline V-NR & 333 & 0.173 & 11.1 & 930 & 0.13 \\
\hline
\end{tabular}

Many have been models employed for evaluating the performances of magnetocaloric, electrocaloric materials or, at least, single-effect materials [37-43]; on no account about a model able to work with materials presenting different types of caloric effects. In this paper by means of a twodimensional mathematical model an analysis is performed with the most performing, elastocaloric and barocaloric materials in to explore the potential of mechanocaloric cooling.

\section{MATERIALS AND METHODS}

The model employed for the presented investigation is a two-dimensional numerical model of an ACR operating at room temperature. The regenerator has a rectangular shape $(20 \times 45 \mathrm{~mm})$. The area is filled with 54 parallel plates of caloric material; every plate has a thickness of $0.25 \mathrm{~mm}$. The solid-state material occupies globally $60 \%$ of the total area of the regenerator. The interstitial spaces stacked by each two plates are channel where an auxiliary fluid flows with the purpose of heat transferring. Different sets of equations, describing the ACR cycle in the four phases, are applied to the model. The equations that rule the regenerative fluid flow processes, in both directions, are: the Navier-Stokes for the fluid flow and the energy equations for both the fluid and the solid particles. With the assumptions that the fluid is incompressible, laminar and the viscous dissipation neglected, the equations are:

$$
\left\{\begin{array}{c}
\frac{\partial u}{\partial x}+\frac{\partial v}{\partial y}=0 \\
\frac{\partial u}{\partial t}+u \frac{\partial u}{\partial x}+v \frac{\partial u}{\partial y}=-\frac{1}{\rho_{f}} \frac{\partial p}{\partial x}+v\left(\frac{\partial^{2} u}{\partial x^{2}}+\frac{\partial^{2} u}{\partial y^{2}}\right) \\
\frac{\partial v}{\partial t}+u \frac{\partial v}{\partial x}+v \frac{\partial v}{\partial y}=-\frac{1}{\rho_{f}} \frac{\partial p}{\partial y}+v\left(\frac{\partial^{2} v}{\partial x^{2}}+\frac{\partial^{2} v}{\partial y^{2}}\right) \\
\frac{\partial T_{f}}{\partial t}+u \frac{\partial T_{f}}{\partial x}+v \frac{\partial T_{f}}{\partial y}=\frac{k_{f}}{\rho_{f} C_{f p}}\left(\frac{\partial^{2} T_{f}}{\partial x^{2}}+\frac{\partial^{2} T_{f}}{\partial y^{2}}\right) \\
\frac{\partial T_{s}}{\partial t}=\frac{k_{s}}{\rho_{s} C_{s p}}\left(\frac{\partial^{2} T_{s}}{\partial x^{2}}+\frac{\partial^{2} T_{s}}{\partial y^{2}}\right)
\end{array}\right.
$$

The equations that model the adiabatic field increase/decrease processes are:

$$
\left\{\begin{array}{c}
\rho_{f} C_{f p} \frac{\partial T_{f}}{\partial t}=k_{f}\left(\frac{\partial^{2} T_{f}}{\partial x^{2}}+\frac{\partial^{2} T_{f}}{\partial y^{2}}\right) \\
\rho_{s} C_{s p} \frac{\partial T_{S}}{\partial t}=k_{s}\left(\frac{\partial^{2} T_{s}}{\partial x^{2}}+\frac{\partial^{2} T_{s}}{\partial y^{2}}\right)+Q
\end{array}\right.
$$

They must include caloric effect which increases or decreases the temperature of the solid by the variation of the external field applied to the regenerator. Hence the adiabatic temperature variation $\Delta \mathrm{T}_{\mathrm{ad}}$ is converted into a heat source $\mathrm{Q}$ as:

$Q=Q\left(\right.$ field,$\left.T_{S}\right)=\frac{\rho_{S} C_{s p}\left(\text { field }, T_{S}\right) \Delta T_{a d}\left(\text { field }, T_{S}\right)}{\Delta t}$

Table 2. Mathematical expression for $\mathrm{Q}$ function for the different mechanocaloric materials

\begin{tabular}{cc}
\hline Material & Mathematical expression \\
\hline $\mathrm{Cu}_{68.13} \mathrm{Zn}_{15.74} \mathrm{Al}_{16.14}$ & $Q * \Delta \mathrm{t}=10^{6} *[46.08]$ \\
$\Delta \sigma=0.14 \mathrm{GPa}$ & \\
\hline $\mathrm{NiTi}$ & $Q * \Delta \mathrm{t}=10^{6} *[29.33 * \mathrm{~T}-4471$ \\
$\Delta \sigma=0.9 \mathrm{GPa}$ & $\left.-0.04732 * \mathrm{~T}^{2}\right]$ \\
\hline$\left(\mathrm{NH}_{4}\right)_{2} \mathrm{MoO}_{2} \mathrm{~F}_{4}$ & $Q * \Delta \mathrm{t}=10^{6} *[96.92+0.4259$ \\
$\Delta \mathrm{p}=0.9 \mathrm{GPa}_{2}$ & $* \sin (0.2341 * \mathrm{~T})-0.2063 * \mathrm{~T}]$ \\
\hline$\left(\mathrm{NH}_{4}\right)_{2} \mathrm{MoO}_{2} \mathrm{~F}_{4}$ & $Q * \Delta \mathrm{t}=10^{6} *[1.088+0.2777$ \\
$\Delta \mathrm{p}=0.7 \mathrm{GPa}$ & $* \cos (0.3995 * \mathrm{~T})-85.38$ \\
& $\left.-0.002365 * \mathrm{~T}^{2}\right]$ \\
\hline$\left(\mathrm{NH}_{4}\right)_{2} \mathrm{MoO}_{2} \mathrm{~F}_{4}$ & $Q * \Delta \mathrm{t}=10^{6} *[133.4+10.7$ \\
$\Delta \mathrm{p}=0.5 \mathrm{GPa}$ & $* \cos (351.5 * \mathrm{~T})-0.3822 * \mathrm{~T}$ \\
& $-0.03769 * \mathrm{~T} * \cos (351.5 * \mathrm{~T})]$ \\
\hline $\mathrm{MnCoGe} 0.99 \mathrm{In} \mathrm{n}_{0.01}$ & $Q * \Delta \mathrm{t}=10^{6} *[-31.83-$ \\
$\Delta \mathrm{p}=0.3 \mathrm{GPa}$ & $\left.34.34 * \cos \left(0.0002128 * \mathrm{~T}^{2}\right)\right]$ \\
\hline $\mathrm{V}-\mathrm{NR}$ & $Q_{\text {comp }} * \Delta \mathrm{t}=10^{6} *[1.362+0.06056$ \\
$\Delta \mathrm{p}=0.173 \mathrm{GPa}$ & $* T+0.242 * \cos (0.272 * T)$ \\
& $-0.2702 * \cos (0.2129-0.2714 * T]$ \\
& $Q_{\text {decomp }} * \Delta \mathrm{t}=10^{6} *[0.07074 * T$ \\
& $+0.0911 * \sin (1282 * T)-0.4934]$ \\
\hline
\end{tabular}

Q has the dimensions of a power density and it is included in the solid energy equation [44]. It is positive during field increase, negative during field decrease. $\mathrm{Q}$ is a mathematical expression obtained by elaboration and manipulation of experimental data of $\mathrm{C}$ (field, $\mathrm{T}$ ) and $\Delta \mathrm{T}_{\mathrm{ad}}($ field, $\mathrm{T})$, available from scientific literature, by the help of a mathematical finder software. To provide a detailed framework of model building with reference to the investigation performed, in Table 2 are 
reported the $\mathrm{Q} * \Delta \mathrm{t}$ function obtained from the experimental data and employed in the field-changing processes of AeR/BCR cycle.

The coupled equations that govern the AeR (Active elastocaloric Regenerative cycle) or the ABR (Active Barocaloric Regenerative cycle) cycle, imposed on this model, are solved using Finite Element Method. The AeR/BCR cycle is modeled as four sequential steps. The same time step $\Delta t$ has been chosen for the resolution during all the four periods of the cycle. The cycle is repeated several times with constant operating frequency until the regenerator reaches steady state operation.

The purpose of the investigation introduced is to compare the energy performances of the ACR regenerator while it employs one by one the caloric refrigerants [45]. The most salient energy parameters evaluated are the followings:

$\Delta T_{\text {span }}=T_{H}-\frac{1}{\tau} \int_{3 \tau}^{4 \tau} T_{f}(0, y, t) d t$

$\Delta T_{\text {span }}$ quantifies the temperature span across the Active caloric regenerator at the end of a steady-state hot-to-cold flow step.

Cooling power measures the power at which cooling system removes heat:

$\dot{Q}_{\text {ref }}=\frac{1}{\theta} \int_{3 \tau}^{4 \tau} \dot{m}_{f} C_{f}\left(T_{C}-T_{f}(0, y, t)\right) d t$

Coefficient of performances is evaluated as:

$C O P=\frac{\dot{Q}_{r e f}}{\dot{Q}_{r e j}-\dot{Q}_{r e f}+\dot{W}_{p}}$

where $\dot{Q}_{r e j}$ and $\dot{W}_{p}$ are estimated as:

$\dot{Q}_{r e j}=\frac{1}{\theta} \int_{\tau}^{2 \tau} \dot{m}_{f} C_{f}\left(T_{f}(L, y, t)-T_{H}\right) d t$

$\dot{W}_{p}=\frac{\dot{m}\left(\Delta p_{C F}+\Delta p_{H F}\right)}{\eta_{p} \rho_{f}}$

\section{RESULTS}

The ranges where external applied fields vary are related to the particular mechanocaloric material under test, the operating conditions under which the simulations have been done are common for all the materials. Fixed are: the active caloric cycle frequency $(1.25 \mathrm{~Hz})$, cold and hot heat exchanger temperature $\left(\mathrm{T}_{\mathrm{C}}=287 \mathrm{~K}, \mathrm{~T}_{\mathrm{H}}=295 \mathrm{~K}\right)$ while fluid flow rate was varied in the range $0.034 \div 0.057 \mathrm{~kg} / \mathrm{s}$.

The results are reports as a function of the utilization factor $\Phi$ defined as:

$\Phi=\frac{\dot{m}_{f} C_{f} \Delta t}{m_{s} C_{s}}$

This dimensionless number is fundamental [46-48] in the design of a prototype because it represents the ratio of the thermal mass of the secondary fluid to the total thermal mass of the solid regenerator.

In Figure $2 \Delta T_{\text {span }}$ are reported the as a function of the utilization factor for elastocaloric materials. From the plotted data it is evident that all the values follow between 14 and 16 K.

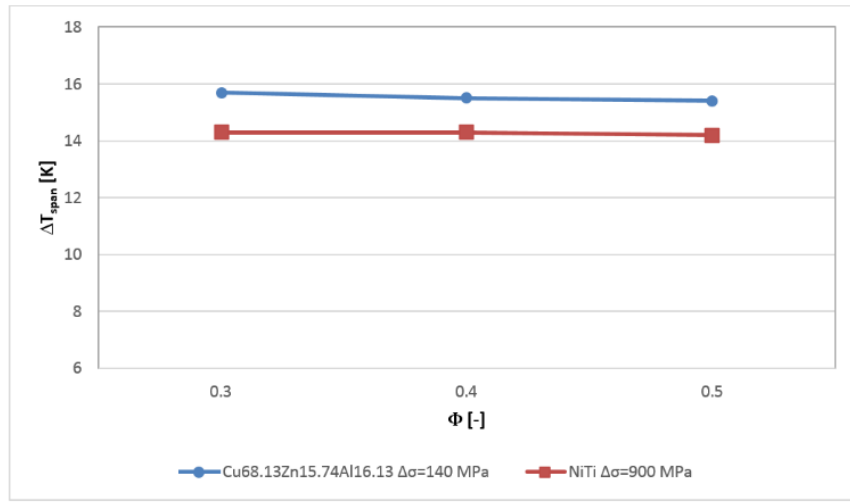

Figure 2. $\Delta T_{\text {span }}$ as a function of $\Phi$ for elastocaloric materials

In Figure 3 are reported $\Delta T_{\text {span }}$ as a function of the utilization factor for barocaloric materials. Figure clearly shows that for each barocaloric material $\Delta T_{\text {span }}$ is an increasing function of the maximum hydrostatic pressure. The best barocaloric material is $\left(\mathrm{NH}_{4}\right)_{2} \mathrm{MoO}_{2} \mathrm{~F}_{4}$ with $\Delta \mathrm{p}=0.9$ $\mathrm{GPa}$, that reaches $\Delta \mathrm{T}_{\text {span }}$ values following in the range 15-16 $\mathrm{K}$ similar to those of the best elastocaloric material $\mathrm{Cu}_{68.13} \mathrm{Zn}_{15.74} \mathrm{Al}_{16.14}$.

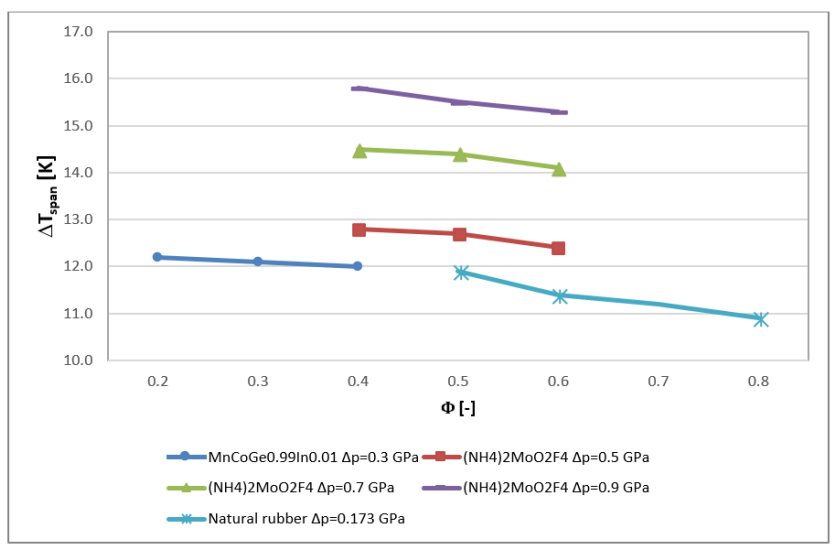

Figure 3. $\Delta T_{\text {span }}$ as a function of $\Phi$ for barocaloric materials

Figures 4 and 5 report $\mathrm{Q}_{\text {ref }}$ vs $\Phi$ trends for elastocaloric and barocaloric materials, respectively. The elastocaloric materials overperforms the barocaloric ones. The best barocaloric material, $\left(\mathrm{NH}_{4}\right)_{2} \mathrm{MoO}_{2} \mathrm{~F}_{4}$ with $\Delta \mathrm{p}=0.9 \mathrm{GPa}$, show $\mathrm{Q}_{\text {ref }}$ values within 260 and $460 \mathrm{~W}$ similar to those of the best elastocaloric material $\mathrm{Cu}_{68.13} \mathrm{Zn}_{15.74} \mathrm{Al}_{16.14}$.

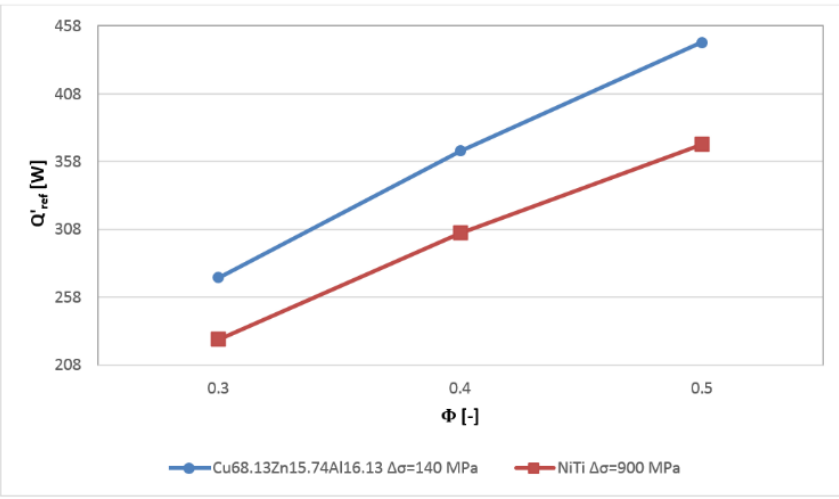

Figure 4. $\dot{Q}_{\text {ref }}$ as a function of $\Phi$ for elastocaloric materials 


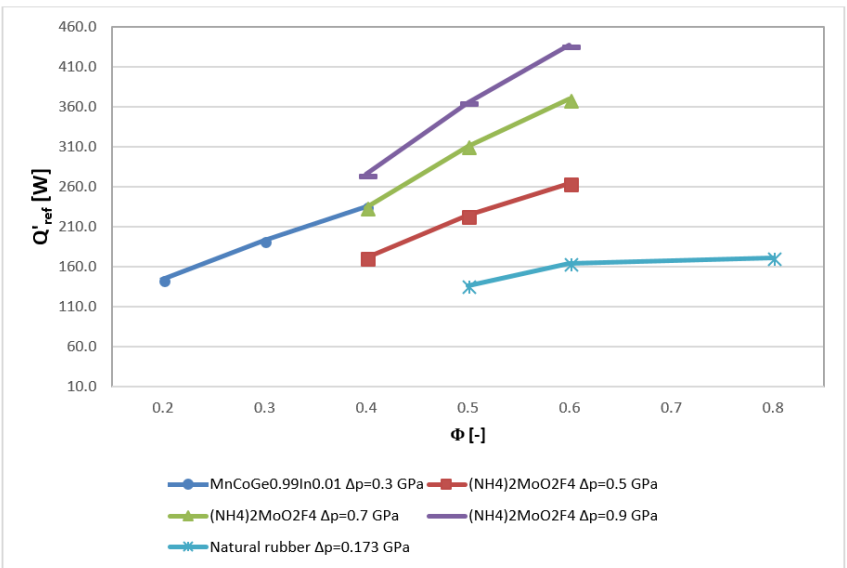

Figure 5. $\dot{Q}_{\text {ref }}$ as a function of $\Phi$ for barocaloric materials

In Figures 6 and 7 are reported the COP values for elastocaloric and barocaloric materials, respectively. From the data reported in the figures it is clear that the best mechanocaloric materials provide energy performances better than those of traditional vapour compression plants. In particular, with $\mathrm{Cu}_{68.13} \mathrm{Zn}_{15.74} \mathrm{Al}_{16.14}$ and $\left(\mathrm{NH}_{4}\right)_{2} \mathrm{MoO}_{2} \mathrm{~F}_{4}$, the COP values follow within the range 7-11.

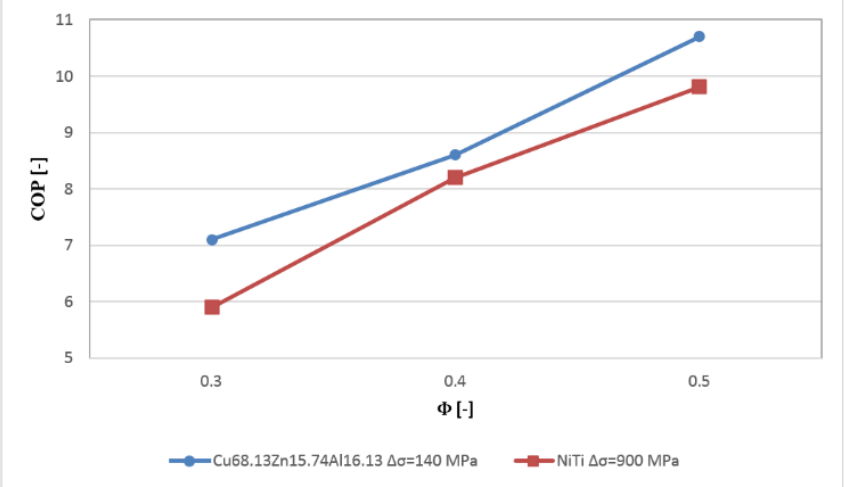

Figure 6. $C O P$ as a function of $\Phi$ for elastocaloric materials

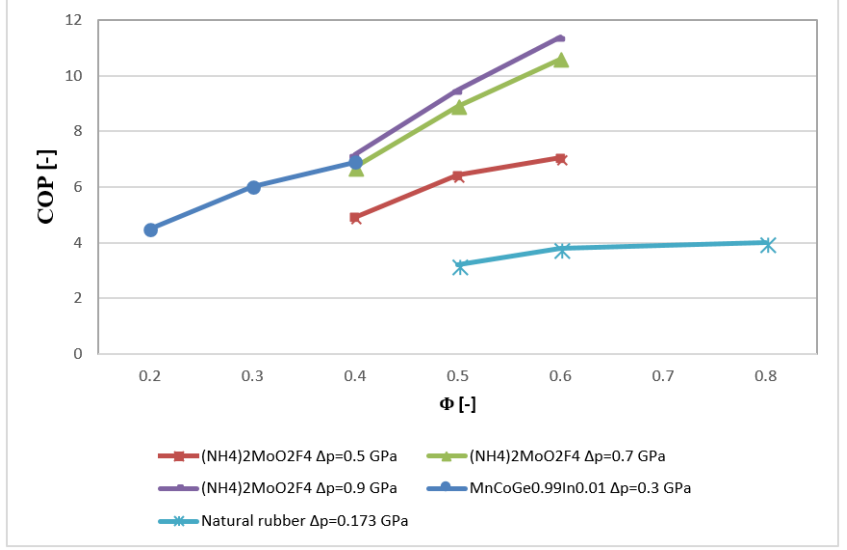

Figure 7. $C O P$ as a function of $\Phi$ for barocaloric materials

\section{CONCLUSIONS}

The energy performances of mechanocaloric materials, employed as caloric refrigerant, have been evaluated and introduced in the present paper. The most promising elastocaloric or barocaloric materials have been tested at room temperature varying the utilization factor. Results collected reveal that elastocaloric materials slightly overperform barocaloric ones but almost all gives more promising performances than actual vapor compression coolers. Thus, mechanocaloric cooling could be well considered as cooling technique of tomorrow.

\section{REFERENCES}

[1] Aprea C, Greco A, Maiorino A, Masselli C. (2018). The drop-in of HFC134a with HFO1234ze in a household refrigerator. International Journal of Thermal Sciences 127:

$117-125$ https://doi.org/10.1016/j.ijthermalsci.2018.01.026

[2] Aprea C, Greco A, Maiorino A, Masselli C, Metallo A. (2016). HFO1234yf as a drop-in replacement for R134a in domestic refrigerators: a life cycle climate performance analysis. International Journal of Heat and Technology 34:

S212-S218. https://doi.org/10.18280/ijht.34S204

[3] Aprea C, Greco A, Maiorino A, Masselli C, Metallo A. (2016). HFO1234ze as drop-in replacement for R134a in domestic refrigerators: An environmental impact analysis. Energy Procedia 101: 964-971. https://doi.org/10.1016/j.egypro.2016.11.122

[4] Scafetta N, Mirandola A, Bianchini A. (2017). Natural climate variability, part 1: Observations versus the modeled predictions. International Journal of Heat and Technology 35: S9-S17. https://doi.org/10.18280/ijht.35Sp0102

[5] Poolsawat K, Wongsapai W. (2018). Effects of household-related factors on residential direct $\mathrm{CO}_{2}$ emissions in Thailand from 1993 to 2015: A decomposition analysis. Chemical Engineering Transactions 63: 337-342. https://doi.org/10.3303/CET1863057

[6] Polonara F, Kuijpers L, Peixoto R. (2017). Potential impacts of the Montreal Protocol Kigali Amendment to the choice of refrigerant alternatives. International Journal of Heat and Technology 35: S1-S8. https://doi.org/10.18280/ijht.35Sp0101

[7] Aprea C, Greco A. (1998). An experimental evaluation of the greenhouse effect in R22 substitution. Energy Conversion and Management 39(9): 877-887. https://doi.org/10.1016/S0196-8904(97)10058-9

[8] Lassandro P, Di Turi S. (2017). Energy efficiency and resilience against increasing temperatures in summer: the use of PCM and cool materials in buildings. International Journal of Heat and Technology 35: S307S315. https://doi.org/10.18280/ijht.35Sp0142

[9] Sari EN, Prueksakorn K, Gonzalez JC, Arpornthip T, Areerob T, Pornsawang C, Pimonsree S. (2018). Inventory of greenhouse gas emissions for Phayao province-an agricultural city in Thailand. Chemical Engineering Transactions 63: 163-168. https://doi.org/10.3303/CET1863028

[10] Kitanovski A, Plaznik U, Tomc U, Poredoš A. (2015). Present and future caloric refrigeration and heat-pump technologies. Int. J. of Refrigeration 57: 288-298. https://doi.org/10.1016/j.ijrefrig.2015.06.008

[11] Planes A, Stern-Taulats E, Castán T, Vives E, Mañosa L, Saxena A. (2015) Caloric and multicaloric effects in 
shape memory alloys. Materials Today: Proceedings 2: S477-S484. https://doi.org/10.1016/j.matpr.2015.07.332

[12] Fähler S, Rößler U K, Kastner O, Eckert J, Eggeler G, Emmerich H, Entel P, Müller S, Quandt E, Albe K. (2012). Caloric effects in ferroic materials: new concepts for cooling. Adv. Eng. Mat. 14(1-2): 10-19. https://doi.org/10.1002/adem.201100178

[13] Pecharsky VK, Gschneidner Jr. KA. (1999). Magnetocaloric effect and magnetic refrigeration. J. of Magn. and Magn. Mat. 200(1-3): 44-56. https://doi.org/10.1016/S0304-8853(99)00397-2

[14] Aprea C, Greco A, Maiorino A. (2015). GeoThermag: A geothermal magnetic refrigerator. Int. J. of Refrig. 59: 75-83. https://doi.org/10.1016/j.ijrefrig.2015.07.014

[15] Aprea C, Greco A, Maiorino A. (2017). An application of the artificial neural network to optimise the energy performances of a magnetic refrigerator. Int. J. of Refrigeration 82: 238-251. https://doi.org/10.1016/j.ijrefrig. 2017.06.015

[16] Ju YS. (2010). Solid-state refrigeration based on the electrocaloric effect for electronics cooling. J. of Electronic Packaging 132(4): 041004. https://doi.org/10.1115/1.4002896

[17] Tusek J, Engelbrecht K, Millán-Solsona R, Mañosa L, Vives E, Mikkelsen LP, Pryds N. (2015). The elastocaloric effect: a way to cool efficiently. Adv. En. Mat. 5(13). https://doi.org/10.1002/aenm.201500361

[18] Strässle T, Furrer A, Dönni A, Komatsubara T. (2002). Barocaloric effect: The use of pressure for magnetic cooling in Ce $3 \mathrm{Pd} 20$ Ge 6. Journal of Applied Physics 91(10): 8543-8545. https://doi.org/10.1063/1.1456450

[19] Rowe AM, Barclay JA. (2003). Ideal magnetocaloric effect for active magnetic regenerators. J. of Appl. Physics 93(3): 1672-1676. https://doi.org/10.1063/1.1536016

[20] Aprea C, Greco A, Maiorino A, Masselli C. (2015). A comparison between rare earth and transition metals working as magnetic materials in an AMR refrigerator in the room temperature range. Appl. Thermal Eng. 91: 767-777.

https://doi.org/10.1016/j.applthermaleng.2015.08.083

[21] Sandeman KG. (2012). Magnetocaloric materials: The search for new systems. Scripta Materialia 67(6): 566571. https://doi.org/10.1016/j.scriptamat.2012.02.045

[22] Phan MH, Yu SC. (2007). Review of the magnetocaloric effect in manganite materials. Journal of Magnetism and Magnetic Materials 308(2): 325-340. https://doi.org/10.1016/j.jmmm.2006.07.025

[23] Aprea C, Greco A, Maiorino A, Masselli C. (2017). A comparison between electrocaloric and magnetocaloric materials for solid state refrigeration. International Journal of Heat and Technology 35(1): 225-234. https://doi.org/10.18280/ijht.350130

[24] Aprea C, Greco A, Maiorino A, Masselli C. (2016) A comparison between different materials in an active electrocaloric regenerative cycle with a $2 \mathrm{D}$ numerical model. Int. J. of Refrigeration 69: 369-382. https://doi.org/10.1016/j.ijrefrig.2016.06.016

[25] Lu SG, Zhang Q. (2009). Electrocaloric materials for solid - state refrigeration. Advanced Materials 21(19): 1983-1987. https://doi.org/10.1002/adma.200802902

[26] Coey JMD. (2012). Permanent magnets: Plugging the gap. Scripta Materialia 67(6): 524-529. https://doi.org/10.1016/j.scriptamat.2012.04.036
[27] Aprea C, Greco A, Maiorino A, Mastrullo R, Tura A. (2014). Initial experimental results from a rotary permanent magnet magnetic refrigerator. Int. J. of Refrig. 43:

111-122. https://doi.org/10.1016/j.ijrefrig.2014.03.014

[28] Aprea C, Greco A, Maiorino A, Masselli C. (2016). The energy performances of a rotary permanent magnet magnetic refrigerator. Int. J. of Refrig. 61: 1-11. https://doi.org/10.1016/j.ijrefrig.2015.09.005

[29] Aprea C, Cardillo G, Greco A, Maiorino A, Masselli C. (2016). A rotary permanent magnet magnetic refrigerator based on AMR cycle. Appl. Thermal Eng. 101: 699-703. https://doi.org/10.1016/j.applthermaleng.2016.01.097

[30] Qian S, Geng Y, Wang Y, Ling J, Hwang Y, Radermacher R, Takeuchi I, Cui J. (2016). A review of elastocaloric cooling: materials, cycles and system integrations. International $\mathrm{J}$ of Refrigeration 64: 1-19. https://doi.org/10.1016/j.ijrefrig.2015.12.001

[31] Mañosa L, Planes A, Acet M. (2013). Advanced materials for solid-state refrigeration. J. of Materials Chemistry A 1(16): 4925-4936. https://doi.org/10.1039/b000000x

[32] Tusek J, Engelbrecht K, Millán-Solsona R, Mañosa L, Vives E, Mikkelsen LP, Pryds N. (2015). The elastocaloric effect: A way to cool efficiently. Adv. En. Mat. 5(13). https://doi.org/10.1002/aenm.201500361

[33] Strässle T, Furrer A, Dönni A, Komatsubara T. (2002). Barocaloric effect: The use of pressure for magnetic cooling in Ce $3 \mathrm{Pd} 20 \mathrm{Ge} 6$. Journal of Applied Physics 91(10): 8543-8545. https://doi.org/10.1063/1.1456450

[34] Gorev MV, Bogdanov EV, Flerov IN, Kocharova AG, Laptash NM. (2010). Investigation of thermal expansion, phase diagrams, and barocaloric effect in the $\left(\mathrm{NH}_{4}\right) 2$ WO $2 \mathrm{~F} 4$ and (NH 4) 2 Mo O 2 F 4 oxyfluorides. Physics of the Solid State 52(1): 167-175. https://doi.org/10.1134/S1063783410010294

[35] Wu RR, Bao LF, Hu FX, Wu H, Huang QZ, Wang J, Dong XL, Li GN, Sun JR, Shen FR, Zhao TY, Zheng XQ, Wang LC, Liu Y, Zuo WL, Zhao YY, Zhang M, Wang XC, Jin CQ, Rao GH, Han XF, Shen BG. (2015). Giant barocaloric effect in hexagonal Ni 2 In-type MnCo-Ge-In compounds around room temperature. Scientific Reports 5. https://doi.org/18027. $10.1038 /$ srep 18027

[36] Usuda EO, Bom NM, Carvalho AMG. (2017). Large barocaloric effects at low pressures in natural rubber. European Polymer Journal 92: 287-293. https://doi.org/10.1016/j.eurpolymj.2017.05.017

[37] Aprea C, Greco A, Maiorino A. (2011). A numerical analysis of an active magnetic regenerative cascade system. Int. J. of Energy Research 35(3): 177-188. https://doi.org/10.1002/er.1682

[38] Aprea C, Greco A, Maiorino A. (2011). A numerical analysis of an active magnetic regenerative refrigerant system with a multi-layer regenerator. Energy Conversion and Management 52(1): 97-107. https://doi.org/10.1016/j.enconman.2010.06.048

[39] Aprea C, Greco A, Maiorino A. (2012). Modelling an active magnetic refrigeration system: a comparison with different models of incompressible flow through a packed bed. Applied Thermal Engineering 36: 296-306. 10.1016/j.applthermaleng.2011.10.034

[40] Aprea C, Greco A, Maiorino A. (2013). The use of the 
first and of the second order phase magnetic transition alloys for an AMR refrigerator at room temperature: a numerical analysis of the energy performances. Energy Conversion and Management 70: 40-55. https://doi.org/10.1016/j.enconman.2013.02.006

[41] Aprea C, Greco A, Maiorino A. (2013) A dimensionless numerical analysis for the optimization of an active magnetic regenerative refrigerant cycle. Int. J. of En. Research 37(12):

1475-1487. https://doi.org/10.1002/er.2955

[42] Aprea C, Greco A, Maiorino A, Masselli C. (2017). Analyzing the energetic performances of AMR regenerator working with different magnetocaloric materials: Investigations and viewpoints. International Journal of Heat and Technology 35(Special Issue 1): S383-S390. https://doi.org/10.18280/ijht.35Sp0152

[43] Aprea C, Greco A, Maiorino A, Masselli C. (2018). Energy performances and numerical investigation of solid-state magnetocaloric materials used as refrigerant in an active magnetic regenerator. Thermal Science and Engineering Progress 6: 370-379. https://doi.org/10.1016/j.tsep.2018.01.006

[44] Aprea C, Cardillo G, Greco A, Maiorino A, Masselli C. (2015). A comparison between experimental and 2D numerical results of a packed-bed active magnetic regenerator. Applied Thermal Engineering 90: 376-383. https://doi.org/10.1016/j.applthermaleng.2015.07.020

[45] Aprea C, Greco A, Maiorino A, Masselli C. (2018). Solid-state refrigeration: A comparison of the energy performances of caloric materials operating in an active caloric regenerator. Energy. https://doi.org/10.1016/j.energy.2018.09.114

[46] Eriksen D, Engelbrecht K, Bahl CRH, Bjørk R, Nielsen KK, Insinga AR, Pryds N. (2015). Design and experimental tests of a rotary active magnetic regenerator prototype. Int. J. of Refrig. 58: 14-21. https://doi.org/10.1016/j.ijrefrig.2015.05.004

[47] Trevizoli PV, Barbosa Jr J.R, Ferreira RT. (2011). Experimental evaluation of a Gd-based linear reciprocating active magnetic regenerator test apparatus. Int. J. of Refrig. 34(6): 1518-1526. https://doi.org/10.1016/j.ijrefrig.2011.05.005

[48] Plaznik U, Tušek J, Kitanovski A, Poredoš A. (2013). Numerical and experimental analyses of different magnetic thermodynamic cycles with an active magnetic regenerator. Applied Thermal Engineering

59(1-2):

$52-59$.

https://doi.org/10.1016/j.applthermaleng.2013.05.019

\section{NOMENCLATURE}

C

$\mathrm{k}$

m'

$\mathrm{p}$

Q

$\mathrm{S}$

$\mathrm{T}$

$\mathrm{t}$

$\mathrm{u}$

$\mathrm{V}$

W'

$\mathrm{X}$

Y

\section{Greek symbols}

$\Delta$

$\varepsilon$

$\eta$

$\mu$

$\Phi$

$v$

$\rho$

$\sigma$

$\tau$

\section{Subscripts}

0

1

ad

C

CF

$\mathrm{F}$

$\mathrm{H}$

$\mathrm{HF}$

$\mathrm{P}$

ref

rej

$\mathrm{s}$
Specific heat, $\mathrm{J}^{\mathrm{kg}^{-1}}$. $\mathrm{K}^{-1}$

thermal conductivity, W. $\mathrm{m}^{-1} \cdot \mathrm{K}^{-1}$ mass rate, kg. $\mathrm{s}^{-1}$

pressure, $\mathrm{Pa}$

thermal power, $\mathrm{W}$

entropy, $\mathrm{J}^{\mathrm{kg}^{-1}} \cdot \mathrm{K}^{-1}$

temperature, $\mathrm{K}$

time, $\mathrm{s}$

longitudinal fluid velocity, $\mathrm{m} . \mathrm{s}^{-1}$

orthogonal fluid velocity, $\mathrm{m} . \mathrm{s}^{-1}$

mechanical power, $\mathrm{W}$

conjugate field

applied driving field

finite difference

strain, $\mathrm{N}$

efficiency, -

dynamic viscosity, $\mathrm{kg} \cdot \mathrm{m}^{-1} \cdot \mathrm{s}^{-1}$

utilization factor, -

cinematic viscosity, $\mathrm{m}^{+2} \cdot \mathrm{s}^{-1}$

density, $\mathrm{kg} . \mathrm{m}^{-3}$

stress, $\mathrm{Pa}$

time period of the cycle, $\mathrm{s}$

minimum

maximum

Adiabatic

cold heat exchanger

cold to ho fluid flow

fluid

hot heat exchanger

hot to cold fluid flow

constant pressure

refrigerant

rejected

solid 